УДК: 378.015 .311

DOI:

Марія Клепар, доктор педагогічних наук, професор кафедри педагогіки початкової освіти ДВНЗ "Прикарапатський Наиіональний університет імені Василя Стефаника"

Тетяна Потапчук, доктор педагогічних наук, професор, професор кафедри теорії та методики дошкільної і спеціальної освіти ДВНЗ "Прикарпатський національний університет імені Василя Стефаника" Надія Кравець, кандидат педагогічних наук, доцент кафедри теорії та методики дошкільної і спечіальної освіти

ДВНЗ "Прикарпатський наиіональний університет імені Василя Стефаника"

\title{
ВИХОВНИЙ ПОТЕНЦІАЛ ПОЗААУДИТОРНОЇ ДІЯЛЬНОСТІ У ФОРМУВАННІ ЕСТЕТИЧНОЇ КУЛЬТУРИ МАЙБУТНІХ ПЕДАГОГІВ
}

У статті подано, щуо позааудиторна діяльність має важливе значення у формуванні естетичноі культури майбутніх педагогів, особливо ї̈ впливу на формування особистості, і є однією з актуальних проблем педагогічної науки.

Відзначено, що становлення Украӥнської держави органічно пов'язане з увиразненням пріоритетів духовної культури суспільства. Сьогодні особливої актуальності набуло питання про культурний стан студентської молоді як однієї з продуктивних сочіальних верств населення. Складність його розв'язання полягає у тому, щуо навколишнє сочіальне й культурне життя мало надає стимулів до виявлення естетичного досвіду, а навпаки, часто сприяє орієнтації на антикультурні ичінності. 3 огляду на таке постала невідкладна потреба розвитку загальної культури майбутніх фахівців, зокрема естетичної культури, яка втратила статусу одного з найважливіших аспектів соиіального та духовного розвитку особистості. У иььом контексті особливо важливим є формування естетичної культури майбутніх педагогів, адже рівень естетичної культури вчителя є одним із показників його професійної компетентності, від якої залежить формування духовного світу студентів, розвитку їхньӧ свідомості й самосвідомості.

Ключові слова: естетична культура; майбутні педагоги; позааудиторна діяльність; естетичні здібності; художня творчість.

תim. 19.

Mariya Klepar, Doctor of Sciences (Pedagogy), Professor of the Pedagogy of Primary Education Department, Vasyl Stefanyk Precarpathian National University Tetyana Potapchuk, Doctor of Sciences (Pedagogy), Professor, Professor of the Theories and Methods of Preschool and Special Education Department Vasyl Stefanyk Precarpathian National University

Nadiya Kravets, Ph.D. (Pedagogy), Associate Professor of the Theories and Methods of Preschool and Special Education Department Vasyl Stefanyk Precarpathian National University

\section{AN EDUCATIONAL POTENTIAL OF EXTRACURRICULAR ACTIVITY IN THE FORMATION OF AESTHETIC CULTURE OF FUTURE TEACHERS}

The article presents that extracurricular activities are important in the formation of aesthetic culture of future teachers, especially its impact on the formation of personality and is one of the pressing problems of pedagogical science.

It is noted that the formation of the Ukrainian state is organically connected with the expression of the priorities of the spiritual culture of society. Today the issue of the cultural condition of student youth as one of the productive social strata of the population has become especially relevant. The difficulty of solving it is that the surrounding social and cultural life provides little incentive to discover aesthetic experience, but on the contrary, often contributes to the focus on anti-cultural values. Given this, there was an urgent need to develop the general culture of future professionals, in particular their aesthetic culture, which has lost its status as one of the most important aspects of social and spiritual development of the individual. In this context, the formation of aesthetic culture of future teachers is especially important, because the level of aesthetic culture of a teacher is one of the indicators of his professional competence, which depends on the formation of the students' spiritual world, development of their consciousness and self-awareness. The modernization of the educational space requires specialists who would use not only professional knowledge in their pedagogical activities, but also skillfully use the means of aesthetic and educational influence. The need to revise the basic principles, forms and methods of development of 


\section{ВИХОВНИЙПОТЕНЦІАЛПОЗААУДИТОРНОЇ ДІЯЛЬНОСТІ У ФОРМУВАННІ ЕСТЕТИЧНОӤ КУЛЬТУРИ МАЙБУТНІХПЕДАГОГІВ}

aesthetic culture of students of higher education institutions is also tangible. One of the effective means of forming the aesthetic culture of future teachers is extracurricular activities, cognitive and aesthetic functions of which have significant educational potential. Involvement of students in artistic creativity has a qualitative effect on the effective filling of their leisure, satisfaction of needs, interests, promotes the identification and implementation of aesthetic abilities, which helps in the training of creative, qualified professionals.

Keywords: aesthetic culture; future teachers; extracurricular activities; aesthetic abilities; artistic creativity.

$\Pi$ остановка проблеми та наліз основних досліджень і публікацій. Позааудиторну діяльність науковці досліджували в різних напрямах і визначають як чинник. Розглянемо найпоширеніші: К. Галацин формування комунікативної культури студентів; Н. Галєєва - розвитку творчої обдарованості особистості; О. Медведєва - формування і розвитку творчих умінь студентів; Н. Руденко та О. Тепла- формування міжособистісних взаємин студентів та ї гуманістичних цінностей. Актуальними у вивченні даної проблеми $є$ праці Р. Абдулова; І. Беха; Н. Волкової; О.В. Коваль та ін.

Мета дослідження - на основі теоретичного аналізу проблеми дослідження обгрунтувати виховний потенціал позааудиторної діяльності у формуванні естетичної культури майбутніх педагогів.

Для розв'язання поставлених завдань використано такі теоретичні методи: аналіз і узагальнення наукової і методичної літератури 3 досліджуваної проблеми. Відповідно до мети та гіпотези визначено такі задачі дослідження: 3'ясувати стан дослідженості проблеми, уточнити сутність поняття “естетична культура майбутніх педагогів" та виявити культурно-виховний потенціал позааудиторної діяльності.

Виклад основного матеріалу. Серед науковців немає однієї думки щодо визначення поняття “позааудиторна діяльність". Р. Абдулов [1], І. Зелена [2], Н. Козліковська [4], Л. Онучак [8], Н. Скрипник [14] розглядають позааудиторну діяльність як основну складову частину або підсистему виховної системи закладу освіти. Інші - В. Коваль [3], Л. Петриченко [11], С. Шехавцова [18] зазначають, що позааудиторна діяльність $€$ цілісним, загальнопедагогічним процесом $\mathrm{i}$ охоплює всю освітньо-виховну діяльність. Отже, існують два основні підходи до розгляду позааудиторної діяльності як до складової виховної роботи та складника освітнього процесу. Всі форми позааудиторної діяльності студентів об'єднує те, що вони знаходяться поза розкладом навчальних занять. Позааудиторну діяльність розглядають як необхідну складову цілісного освітнього процесу, тому що вона вміщує різні заходи навчального і виховного характеру [13]. У педагогічному розумінні діяльність розуміється як активна взаємодія з навколишньою дійсністю, у ході якої особистість виступає як суб'єкт, ціленаправлено діючий на об'єкт та який задовольняє таким чином свої потреби [9].

Ми вже вказували, що серед науковців немає єдиної думки щодо визначення поняття “позааудиторна діяльність", у більшості випадків вони оперують поняттями "позакласна виховна робота" та "позаурочна навчальна робота" [15].

Отже, позааудиторна робота студентів - це процес, в якому домінує елемент самореалізації, який дає змогу студентам гармонізувати внутрішні та зовнішні фактори формування професійної культури, створює додаткові умови для реалізації внутрішнього потенціалу, задоволення тих потреб, які в процесі аудиторної роботи не задовольняються, тому що позааудиторна робота має бути орієнтована на особистість студента [10].

Відтак, О. Медведєва стверджує, що позааудиторну роботу у ЗВО слід спрямовувати на формування у студентів досвіду творчої діяльності як пріоритетної i розглядає позааудиторну діяльність як сукупність і взаємодію різноманітних форм, методів і засобів виховного впливу на студентів 3 метою становлення їхнього світогляду, формування рис характеру, творчих умінь і навичок [7].

В свою чергу Л. Кондрашова вважає, що в основі підготовки студентів до педагогічної діяльності має лежати їх морально-психологічне виховання через педагогічні вечори, пресконференції з актуальних проблем психології, педагогіки, розмови за “круглим столом", конкурси, усні журнали, педагогічні тижні та ін. [5].

Однак, В. Коваль поєднує навчальну роботу з аудиторною і саме в аудиторії студент навчається, а частину часу для самостійного навчання, називає позааудиторною діяльністю, що $\epsilon$ невід'ємною складовою частиною професійної підготовки і здійснюється поза розкладом навчальних занять, щоб створити умови для самореалізації студента [3].

Позааудиторна діяльність відкриває великі можливості для самореалізації, передбачає досить великий ступінь свободи, завдяки чому здійснюється більш тісне міжособистісне неформальне спілкування студентів, викладачів, а також відбувається культурне і духовне збагачення особистості, розвиток і поглиблення смаків тощо [4]. 
Варто вказати на важливі можливості формування естетичного світогляду, які закладені в різних формах позааудиторної виховної роботи (бесідах на естетичні теми, лекціях, факультативах 3 мистецтва та проблем естетичного виховання, концертах, дискусійних клубах, театралізованих виступах, творчих вечорах, бесідах за круглим столом тощо). Мистецтво є актуальним засобом впливу на розум і почуття людини тому у ЗВО влаштовують походи до музеїв, театрів, кіно, зустрічі 3 художниками, письменниками, акторами, тощо [16].

До найбільш вживаних форм виховної роботи доцільно В. Швирка відносить - бесіди, екскурсії, вікторини, “круглі столи”, ділові зустрічі, дискусії, турніри, тематичні та художні конференції, брифінги, семінари-тренінги, вечори, свята, конкурси, фестивалі, тижні кафедр, обряди, години спілкування, тренінг-курси, інсценування [17].

Контроль за самостійною та позааудиторною роботою студентів може бути опосередкованим або органічно вписаним у навчальний процес. Основними формами та засоби контролю є: семінарські заняття, індивідуально-теоретичні співбесіди, письмові контрольні роботи, передекзаменаційні опитування студентів за допомогою комп'ютера, державні іспити, вивчення основних інтересів, настроїв студентів, тестування [19].

Зі свого боку, Л. Онучак виділяє такі форми роботи зі студентами в позааудиторний час: теоретичні, практичні, комбіновані, а залежно від способу виконання завдань - усні та письмові форми діяльності, які активно використовуються викладачами у роботі зі студентами в позааудиторний час [8]. Л. Петриченко стверджує, що “правильно організована й раціонально спланована позааудиторна робота студента забезпечує найбільш високий рівень засвоєння матеріалу - трансформацію, є засобом активізації інтелектуальної діяльності, розвитку творчих здібностей, формування творчих умінь студента" [11].

Як зазначають Г. Корольова та Г. Петрова, форми естетичного виховання у позааудиторній роботі органічно пов'язані зі змістом виховного процесу, але зберігають відносну самостійність. Зустрічі та тематичні екскурсії розвивають естетичний інтерес до знань, естетичне сприйняття, погляди, смаки та ідеали, а також естетичні почуття, тобто все те, що складає поняття “естетична свідомість”, а отже формують естетичний світогляд майбутніх педагогів [6].
На перших курсах доцільно використовувати традиційні форми естетичного виховання - походи до театрів, музеїв, філармонію; проводити бесіди, тематичні вечори, усні журнали з питань літератури і мистецтва. Усі ці різноманітні форми естетичного виховання розширюють кругозір, естетичні потреби, формують естетичні інтереси. Для середніх курсів - це цілеспрямоване формування естетичних потреб, смаку, творчих інтересів в цілому, можливість продовжувати та розвивати у студентів естетичні потреби та інтереси шляхом проведення бесід 3 мистецтва та організації відповідних диспутів [6]. Під час формування естетичного світогляду у майбутніх педагогів слід використовувати такі активні форми роботи: ігри, конкурси, вистави, інсценування, підготовка до свят. На старших курсах важливо проводити зі студентами кінофільми, організовувати відвідування виставок, театрів, музеїв, причому зовсім не обов'язково цілісним колективом [6].

Висновки та перспективи подальших досліджень. Можемо дійти висновків, що реалізація змісту естетичної підготовки майбутніх педагогів в процесі формування естетичного світогляду передбачає внесення естетичного початку в усі ланки навчально-виховної аудиторної та позааудиторної діяльності. Використання різноманітних форм і засобів естетичного виховання в аудиторній діяльності у 3 ВО $є$ складовою частиною позааудиторної діяльності та створюють обставини, що впливають на формування естетичного світогляду майбутніх педагогів [2].

У різних видах позааудиторної діяльності викладач має змогу використати форми занять, які подобаються і спробувати нові. Під час позааудиторного часу можна познайомити студентів із видатними творами музичного, образотворчого, архітектурного мистецтва, пояснити їх походження, запропонувати інформацію про стилі і напрямки, біографії відомих музикантів, художників, письменників [12].

Отже, позааудиторна робота є складним соціокультурним явищем, в основі якого лежать суспільні традиції та традиції закладу вищої освіти, уточнені вимогами студентської субкультури (студентська субкультура як чинник міжособистісних відносин у студентському середовищі). Це цілеспрямована діяльність студента що сприяє становленню особистості професіонала [3].

Таким чином, можна стверджувати, що: позааудиторна діяльність відбувається у вільний 


\section{ВИХОВНИЙ ПОТЕНЦІАЛ ПОЗААУДИТОРНОЇ ДІЯЛЬНОСТІ У ФОРМУВАННІ ЕСТЕТИЧНОӤ КУЛЬТУРИ МАЙБУТНІХПЕДАГОГІВ}

час студентів; позанавчальна діяльність $\epsilon$ особливим полікультурним середовищем, в якому студенти розвиваються та реалізуються; вона сприяє розвитку особистості в умовах колективного середовища, при цьому студент отримує досвід 3 соціокультурних чи комунікативних умінь та спілкування 3 ровесниками поза межами закладу освіти [18]; позааудиторна діяльність дає широкі можливості щодо естетичного виховання студентів і задачею викладача $\epsilon$ використання цих можливостей та цілеспрямована робота формування естетичної культури майбутніх педагогів [14]. Подальших досліджень потребують можливості позааудиторної діяльності щодо створення умов для особистісного розвитку та самореалізації майбутніх педагогів.

\section{ЛІТЕРАТУРА}

1. Абдулов Р. М. Организация внеаудиторной воспитательной работы со студентами (негосударственные высшие учебные заведения): уч.-метод. пособие. Павлоград : ЗПИЭУ, 2003. $137 \mathrm{c}$.

2. Зелена І. О. Естетична підготовка майбутнього вчителя у навчально-виховній аудиторній та позааудиторній діяльності. Наукові праці Донецького національного технічного університету. Серія: педагогіка, психологія і соціологія. Випуск 5(155). Донецьк, ДонНТУ, 2009. URL: //ea.donntu.edu.ua:8080/jspui/handle/ 123456789/10287

3. Коваль В. Ю. Участь студентства у мистецькій діяльності як засіб виховання культури міжособистісних відносин. Збірник наукових праць. Педагогічні науки / ред. С. С. Барбіна. Херсон, 2009. Вип. 55. С. 282-286.

4. Козліковська Н. Я. Позааудиторна робота як складова вищої освіти. URL: http://www. v m u r o l. com.ua/ u p load/N a u k o vo doslidna\%20robota/Elektronni_vidannya/ Act_problemi/2008/2/39.pdf (дата звернення: 29.09.2017)

5. Кондрашова Л.В. Теоретические основы воспитания нравственно-психологической готовности студентов пединститутов к профессиональной деятельности: дис. ... д-ра пед. наук. Москва, 1989. 363 с.

6. Королева Г.И., Петрова Г.А. Система эстетической подготовки студентов в высших учебных заведениях. Издательство Казанского ун-та, 1984. 182 с.

7. Медведєва О.Р. Формування творчих умінь студентів у позааудиторній виховній роботі: автореф. дис. ... канд. пед. наук / Харківський держ. пед. ун-тім. Г.С. Сковороди: 13.00.04 Харків, 2008. 19 с.

8. Онучак Л. В. Педагогічні умови організації самостійної позааудиторної роботи студентів економічних спеціальностей : дис. ... канд. пед. наук : 13.00.04. Київ, 2002. 200 с.

9. Педагогическая энциклопедия; под. ред. Каирова И.А. Т. 2. Москва. 1965. 968 с.

10. Педагогіка вищої школи : навч. посіб. / 3. Н. Курлянд. Р. І. Хмелюк, А. В Семенова та ін.; за ред. 3.Н. Курлянд. Київ: Знання, 2007. 495 с.

11. Петриченко Л. О. Підготовка майбутнього вчителя початкової школи до інноваційної діяльності в позааудиторній роботі: автореф. дис. ... канд. пед. наук: 13.00.04. Кіровоград, 2007. 20 с.

12. Саєнко Н.В. Культорологічний підхід до навчання іноземних мов у вищих технічних навчальних закладах : монографія. Харків : ХНАДУ, 2008. 344 с.

13. Скрипник Н.С. Структура позааудиторної діяльності студентів. Междисциплинарные исследования в науке и образовании. 2012. № 1. URL: mino.esrae.ru/158-1135

14. Скрипник Н. С. Позааудиторна робота на матеріалі іноземної мови як складова естетичного виховання студентів. Вестник Харьковского национального автомобильно-дорожного университета : сборник научных трудов / МОН Украины, ХНАДУ. Харьков : Из-во ХНАДУ, 2011. Вып. 53. С.53.

15. Словник педагогічних термінів. URL:http:// pidruchniki.com.ua/pedagogika/slovnik pedagogichnih_terminiv (дата звернення: 26.07.2018)

16. Фіцула М.М. Педагогіка вищої школи: навч. посіб. Київ, 2006. 528 с.

17. Швирка В.М. Естетичне виховання майбутнього вчителя-філолога засобами мистецтва: автореф. дис... канд. пед. наук: 13.00.04. Луган. держ. пед. ун-т ім. Т. Шевченка. Луганськ, 2003. 20 с.

18. Шехавцова С.О. Формування соціокультурної компетентності майбутніх учителів іноземної мови у позанавчальній діяльності університету: дис. ...канд. пед. наук : 13.00.04. Луганськ, 2009. 223 с.

19. Яремчук Н.Я. Підготовка студентів класичного університету до виховної діяльності у загальноосвітній школі: дис. ... канд. пед. наук: 13.00.04. Вінниця, 2007. 189 с.

\section{REFERENCES}

1. Abdulov, R. M. (2003). Organizatsiya vneauditornoy vospitatelnoy rabotyi so studentami (negosudarstvennyie vyisshie uchebnyie zavedeniya) [Organization of extracurricular educational work 


\section{ВИХОВНИЙПОТЕНЦАЛ ПОЗААУДИТОРНОЇ ДІЯЛЬНОСТІ У ФОРМУВАННІ ЕСТЕТИЧНОӤ КУЛЬТУРИ МАЙБУТНІХ ПЕДАГОГІВ}

with students (non-state higher education institutions)]. Pavlograd, 137 p. [in Russian].

2. Zelena, I. O. (2009). Estetychna pidhotovka maibutnoho vchytelia u navchalno-vykhovnii audytornii ta pozaaudytornii diialnosti [Aesthetic preparation of the future teacher in educational classroom and extracurricular activities]. Scientific works of Donetsk National Technical University. Series: pedagogy, psychology and sociology. Vol. 5(155). Donetsk. Available at: //ea.donntu. edu.ua:8080/jspui/ handle/123456789/10287 [in Ukrainian].

3. Koval, V. Yu. (2009). Uchast studentstva u mystetskii diialnosti yak zasib vykhovannia kultury mizhosobystisnykh vidnosyn [System of out-of-class activity of students of higher education institutions]. Collection of scientific works. Pedagogical sciences. (Ed.). Ye. S. Barbina. Kherson, Vol. 55. pp. 282286. [in Ukrainian].

4. Kozlikovska, N. Ya. (2008). Pozaaudytorna robota yak skladova vyshchoi osvity [Out-of-class work as a component of higher education]. Available at: http://www.vmurol.com.ua/upload/Naukovo doslidna\%20robota/Elektronni_vidannya/ Act_problemi/2008/2/39.pdf (accessed 29 Sept. 2017) [in Ukrainian].

5. Kondrashov, L.V. (1989). Teoreticheskie osnovyi vospitaniya nravstvenno-psihologicheskoy gotovnosti studentov pedinstitutov k professionalnoy deyatelnosti [Theoretical bases of education of moral and psychological readiness of students of pedagogical institutions for professional activity]. Doctor's thesis. Moscov, 363 p. [in Russian].

6. Koroleva, G.I., \& Petrova, G.A. (1984). Sistema esteticheskoy podgotovki studentov v vyisshih uchebnyih zavedeniyah [System of aesthetic preparation of students in higher education institutions]. Publishing house of Kazan University,182 p. [in Russian].

7. Medvedieva, O.R. (2008). Formuvannia tvorchykh umin studentiv u pozaaudytornii vykhovnii roboti [Formation of students creative skills in extracurricular educational work]. Extended abstract of Candidate's thesis. Kharkiv, 19 p. [in Ukrainian].

8. Onuchak, L. V. (2002). Pedahohichni umovy orhanizatsii samostiinoi pozaaudytornoi roboty studentiv ekonomichnykh spetsialnostei [Pedagogical conditions of organization of independent out-of-class work of students of economic specialties]. Candidate's thesis. Kyiv, 200p. [in Ukrainian].

9. Pedagogicheskaya entsiklopediya (1965). [Pedagogical encyclopedia]. (Ed.).Kairova I.A. Vol. 2. Moscov, 968 p. [in Russian].

10. Kurliand, Z. N., Khmeliuk, R. I. \& Semenova,A. $\mathrm{V}$ et al. (2007). Pedahohika vyshchoi shkoly
[Pedagogy of Higher school: a manual]. (Ed.). Z.N. Kurliand. Kyiv, 495 p.[in Ukrainian].

11. Petrychenko, L. O. (2007). Pidhotovka maibutnoho vchytelia pochatkovoi shkoly do innovatsiinoi diialnosti $\mathrm{v}$ pozaaudytornii roboti [Preparation of the future elementary school teacher for innovative activity in extracurricular work]. Extended abstract of Candidate's thesis. Kirovohrad, 20 p. [in Ukrainian].

12. Saienko, N.V. (2008). Kultorolohichnyi pidkhid do navchannia inozemnykh mov u vyshchykh tekhnichnykh navchalnykh zakladakh [Culturological Approach to Foreign Language Teaching in Higher Technical Institutions]. Kharkiv, 344 p.[in Ukrainian].

13. Skrypnyk, N.S. (2012). Struktura pozaaudytornoi diialnosti studentiv [Out-of-class student activity structure]. Interdisciplinary research in science and education. No. 1. Available at: mino.esrae.ru/ 158-1135. [in Ukrainian].

14. Skrypnyk, N. S. (2011). Pozaaudytorna robota na materiali inozemnoi movy yak skladova estetychnoho vykhovannia studentiv [Out-of-class work on foreign language material as a component of aesthetic education of students]. Bulletin of the Kharkiv National Automobile and Highway University: collection of scientific papers / MES of Ukraine. Kharkov, Vol. 53. p.53. [in Ukrainian].

15. Slovnyk pedahohichnykh terminiv (2018). [Glossary of pedagogical terms]. Available at: http:// pidruchniki.com.ua/pedagogika/slovnik _pedagogichnih_terminiv (accessed 26 July 2018). [in Ukrainian].

16. Fitsula, M.M. (2006). Pedahohika vyshchoi shkoly [Higher Education Pedagogy]. Tutorial. Kyiv, 528 p. [in Ukrainian].

17. Shvyrka, V.M. (2003). Estetychne vykhovannia maibutnoho vchytelia-filoloha zasobamy mystetstva [Aesthetic education of the future teacher-philologist by means of art]. Extended abstract of Candidate's thesis. Luhansk Taras Shevchenko State Pedagogical University. Luhansk, 20p. [in Ukrainian].

18. Shekhavtsova, S.O. (2009). Formuvannia sotsiokulturnoi kompetentnosti maibutnikh uchyteliv inozemnoi movy u pozanavchalnii diialnosti universytetu [Formation of sociocultural competence of future foreign language teachers in extracurricular activities of the university]. Candidate's thesis. Luhansk, 223 p. [in Ukrainian].

19. Iaremchuk, N.Ia. (2007). Pidhotovka studentiv klasychnoho universytetu do vykhovnoi diialnosti u zahalnoosvitnii shkoli [Preparing Classical University Students for Educational Activities in Secondary School]. Candidate's thesis. Vinnytsia,189 p. [in Ukrainian].

Стаття надійшла до редакції 18.06.2020 